(C) 1981. The Genetical Society of Great Britain

\title{
THE TRUE NATURE OF THE NON-ALLELIC INTERACTIONS IN NICOTIANA RUSTICA REVEALED BY ASSOCIATION CROSSES
}

\author{
H. S. POONI and J. L. JINKS \\ Department of Genetics, University of Birmingham, PO Box 363, Birmingham B15 2TT
}

Received 4.iii.81

\section{INTRODUCTION}

JiNKS and JONES (1958) showed that the additive genetic, $[d]$ and the additive $\times$ additive, $[i]$ and additive $\times$ dominance, $[j]$ interaction components of means estimated from the means of two pure-breeding lines $\left(P_{1}\right.$ and $\left.P_{2}\right)$ and of their $F_{1}, F_{2}, B_{1}$ and $B_{2}$ families are functions of the degree of association $(r)$ of alleles of like effect in the parents. Their real magnitudes and signs are therefore revealed only when the alleles of like effect are completely associated $(r=1)$ in the parents. In order to obtain a true picture of the gene action and interaction in Nicotiana rustica we have therefore investigated two crosses between pure breeding lines in which there is a high degree of association for the genes controlling most of the characters of interest.

\section{Material}

The experiment consists of the $P_{1}, P_{2}, F_{1}, F_{2}, B_{1}$ and $B_{2}$ families of the cross between varieties 2 and 12 and between two of the $D$ inbred lines, $D_{10}$ and $D_{17}$. Varieties 2 and 12 are two of the most extreme in the Birmingham collection. They display a high level of non-allelic interaction and produce the most heterotic $F_{1}$ (Jinks, 1954). $\mathrm{D}_{10}$ and $\mathrm{D}_{17}$ are the extreme selections for final height from a random sample of $60 \mathrm{D}$ inbreds derived by single seed descent from the $F_{2}$ of the $\mathrm{V}_{2} \times \mathrm{V}_{12}$ cross (see Jinks et al., 1977). The coefficients of gene association/dispersion in these two pairs of parents estimated as described by Jayasekara and Jinks (1976) as the ratio of the difference between the parental means and the difference between the extremes of the random sample of $\mathrm{D}$ inbred lines for each character are as follows;

\section{Character}

Height-1, $H_{1}$

Height- $2, \mathrm{H}_{2}$

Height-3, $\mathrm{H}_{3}$

Flowering time, $F T$

Height at Flowering, $H F T$

Leaf length, $L L$

Leaf width, $L W$

Final height, $F H$

$\begin{array}{cc}\text { " } r \text { " for } \mathrm{V}_{2} \times \mathrm{V}_{12} & \text { " } r \text { " for } \mathrm{D}_{10} \times \mathrm{D}_{17} \\ 0.45 & 0.82 \\ 0.82 & 0.74 \\ 0.95 & 0.35 \\ 0.59 & 0.85 \\ 0.21 & 0.82 \\ 0.13 & 0.84 \\ 0.25 & 0.96 \\ 0.35 & 0.94\end{array}$

One thousand individually randomised plants were raised for each of the two crosses as part of a much larger experiment during the summer of 
1975. The design used was that of Jinks and Perkins (1969) for equalising the amount of information about the $P_{1}, P_{2}, F_{1}, F_{2}, B_{1}$ and $B_{2}$ family means. The plants were scored in $\mathrm{cm}$ for all the height and leaf measurements while flowering time was scored from date of sowing. The data for each cross were processed separately through the University of Birmingham 1906A computer.

\section{Results}

We shall analyse only those combinations of cross and character where the degree of association is greater than $r=0 \cdot 8$. These are summarised in table 1 where the family means and their standard errors are listed. The standard weighted least squares model fitting procedures were used to find the best fitting model for each combination. A simple additive, dominance model was first tried and was inadequate in every case $\left(\chi_{(3)}^{2}\right.$ testing goodness-of-fit significant).

The perfect fit, six parameter model for digenic interactions was then fitted (Jinks and Jones, 1958). No simpler model would fit seven of the eight combinations. For $H_{1}$, however, a model containing the four parameters, $m,[d],[h]$ and $[l]$ was adequate $\left(\chi_{(3)}^{2}=3.93\right)$. The adequacy of the six parameter model for the remaining seven characters can only be tested by including more generations. On adding the means of the $L_{1}, L_{2}$ and $L_{3}$ generations of an $F_{\infty}$ triple test cross to the analysis, the digenic interaction model proved to be adequate for $H_{2}, H_{3}$ and $F H\left(\chi_{(3)}^{2}\right.$ not significant). For $F T, H F T, L W$ and $L L$, however, it was inadequate $\left(\chi_{(3)}^{2}\right.$ significant) suggesting that more complex effects were also present.

The results of the model fitting (table 2 ) show that the $[l]$ component always takes the opposite sign to $[h]$. For the seven characters for which they are significant $[i]$ and $[j]$ are both positive having the same sign as $[h]$ and the opposite sign to $[l]$. For these seven characters, therefore, $[l]$ opposes all of the other kinds of gene action and interaction.

Jayasekara and Jinks (1976, table 4) have reported similar results for flowering time and height at flowering for the cross between inbred lines $\mathrm{B}_{2}$ and $\mathrm{B}_{35}$ of $N$. rustica where the degree of association/dispersion was also relatively high $(r \geqq 0 \cdot 7)$. The reciprocal situation where $[h],[i]$ and $[j]$ are negative and $[l]$ is positive has only been found in a cross between varieties $\mathrm{V}_{2}$ and $\mathrm{V}_{42}$ for flowering time where there was also a high level of association (Pooni, 1972).

\section{DisCUSSION}

For a single pair of loci all of the known classical non-allelic interactions can be directly equated with a unique combination of relative signs and magnitudes of $d, h, i, j$ and $l$ (Mather and Jinks, 1971). In the general case of many loci with association at some pairs and dispersion at others only two types of non allelic interactions can be recognised; those in which $[h]$ and $[l]$ have the same sign (complementary) and those in which they have opposite signs (duplicates) (Jinks and Jones, 1958). On this basis all of the examples we have analysed show duplicate interactions. But we are now in the unique position of being able to take the magnitudes and signs of our estimates of $[d],[i]$ and $[j]$ at their face values since they are not 


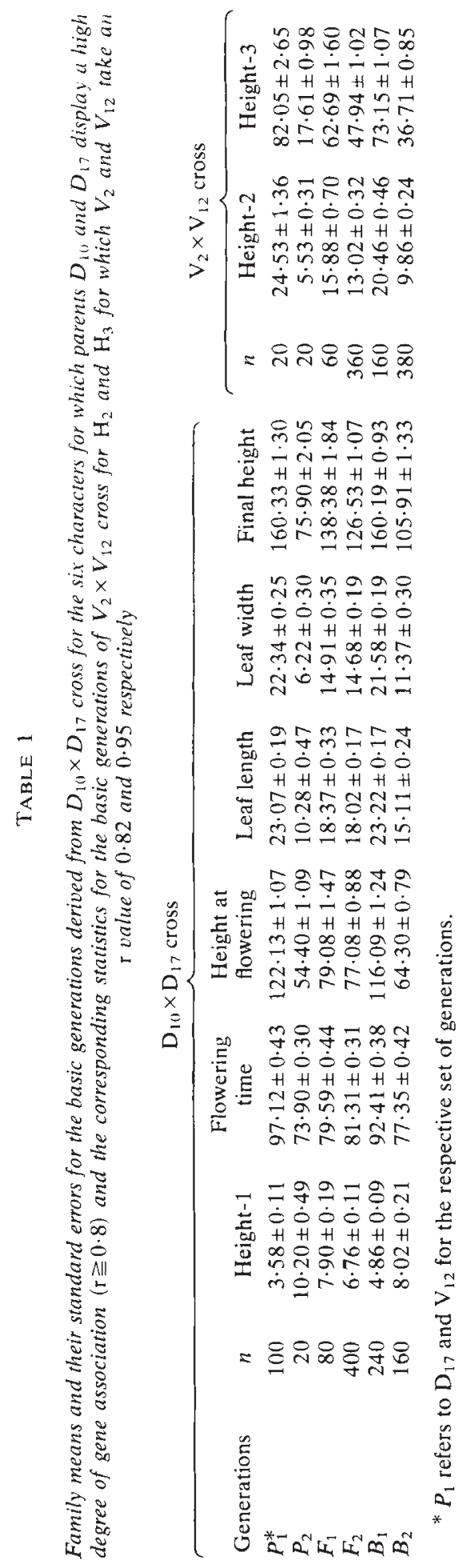




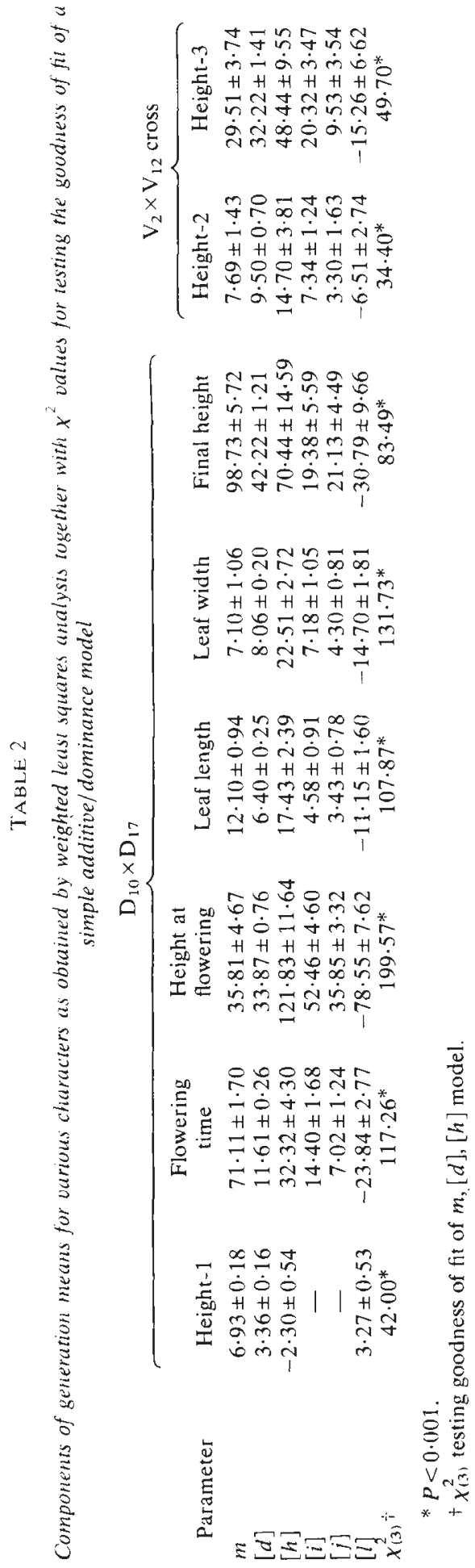


Jistorted by low levels of association. For seven of the eight characters in table 2 (omitting Height-1) $[d],[h],[i]$ and $[j]$ are positive and $[l]$ alone is negative. This is clearly incompatible with duplicate genes which require that $[i],[j]$ and $[l]$ all have the opposite sign to $[h]$ when the distortions due to low levels of association are removed.

To produce these observed relationships we would require that $d_{a}=d_{b}=$ $h_{a}=h_{b}=i_{a b}=j_{a b}=j_{b a}=-l_{a b}$ at the level of a single pair of interacting loci. This does not correspond with any of the classical interactions. It would, for example, lead to a 5:4:7 segregation in an $F_{2}$. This is a modification of the $9: 7$ segregation of classical complementary genes in which the double heterozygote is showing the equivalent of duplicate genes and the rest of the genotypes complementary interactions (fig. 1). The reciprocal situation, observed only in the $\mathrm{V}_{2} \times \mathrm{V}_{42}$ cross for flowering time, is equivalent to $d_{a}=d_{b}=-h_{a}=-h_{b}=-i_{a b}=-j_{a b}=-j_{b a}=l_{a b}$ which is the classical dominant epistasis that produces an $F_{2}$ segregation of $12: 3: 1$ (fig. 1).

(a)

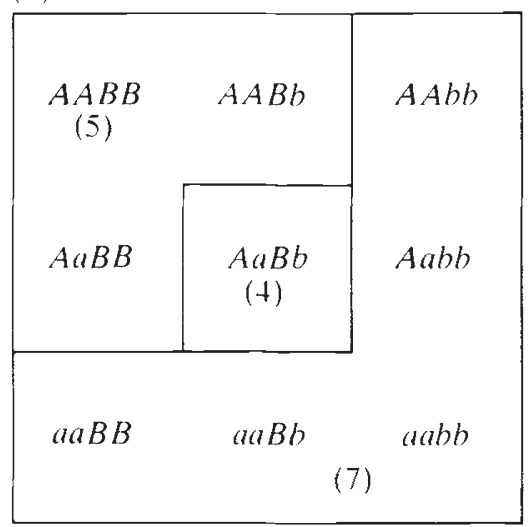

(b)

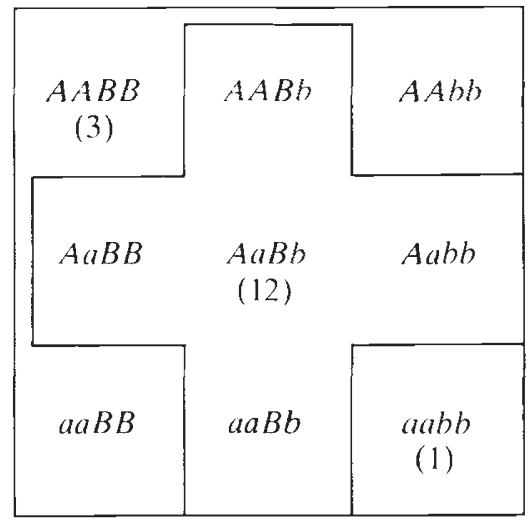

FIG. 1.--Segregation ratios in $F_{2}$ where (a) represents $d_{a}=d_{b}=h_{a}=h_{b}=i_{a b}=j_{a b}=j_{b a}=-l_{a b}$ and (b) represents $d_{a}=d_{b}=-h_{a}=-h_{b}=-i_{a b}=-j_{a b}=-j_{b a}=l_{a b}$. 
These conclusions have profound consequences for understanding the genetical basis of heterosis in Nicotiana rustica and the prospects for producing superior inbred lines. The deviation of the mean of the $F_{1}$ hybric from $m$ is the sum of $[h]$ and $[l]$ and these have opposite signs. The deviation of the best inbred line extractable from the hybrid is the sum of $[d]$ and $[i]$ providing that they are estimated from a cross between associated parents. These have the same sign in the examples in table 2. As a consequence $[d]+[i]>[h]+[l]$ for every character. While, therefore, $V_{2} \times$ $\mathrm{V}_{12}$ is the most heterotic cross, we expect and observe that the best inbred lines extractable from it are superior to the $F_{1}$ for every character.

One last point, by analysing each of the character cross combinations with the lower degree of association we can examine its distorting effects on the significant positive estimates of $[i]$ and $[j]$ given in table 2 . For the seven combinations the lower degree of association makes $[i]$ and $[j]$ negative in three cases and non-significant in four. It would, therefore, have led us to underestimate the importance of the additive $\times$ additive and additive $\times$ dominance components and possibly misinterpret the kind of interaction.

\section{REFERENCES}

JAYASEKARA, N. E. M., AND JINKS, J. L. 1976. Effect of gene dispersion on estimates of components of generation means and variances. Heredity, 36, 31-40.

JINKS, J. L. 1954. The analysis of continuous variation in a diallel cross of Nicotiana rustica varieties. Genetics, 39, 767-788.

JINKS, J. L., JAYASEKARA, N. E. M., AND BOUGHEY, H. 1977. Joint selection for both extremes of mean performance and of sensitivity to a macroenvironmental variable. II. Single seed descent. Heredity, 39, 345-355.

JINKS, J. L., AND JONES, R. M. 1958. Estimation of the components of heterosis. Genetics, 43, 223-234.

JINKS, J. L., AND PERKINS, J. M. 1969. The detection of linked epistatic genes for a metrical trait. Heredity, 24, 465-475.

MATHER, K., AND JINKS, J. L. 1971. Biometrical Genetics. Chapman and Hall, London.

POONI, H. S. 1972. Genotype-environmental interactions in Nicotiana rustica. M.Sc. Thesis. Department of Genetics, University of Birmingham. 